Referencia para citar este artículo: Aliano, N. (2018). La dimensión terapéutica de la experiencia musical: aflicción y trabajo reflexivo en jóvenes fans de un cantante argentino. Revista Latinoamericana de Ciencias Sociales, Niñez y Juventud, 16(1), 255-268. doi:10.11600/1692715x.16115

\title{
La dimensión terapéutica de la experiencia musical: aflicción y trabajo reflexivo en jóvenes fans de un cantante argentino*
}

\author{
NICOLÁS ALIANO ${ }^{* *}$ \\ Profesor Universidad Nacional de San Martín, Argentina.
}

\begin{abstract}
Artículo recibido en mayo 23 de 2017; artículo aceptado en agosto 29 de 2017 (Eds.)
\end{abstract}
- Resumen (analítico): basado en un trabajo de campo etnográfico realizado entre 2008 y 2016 con personas de sectores populares aficionadas a un músico de rock argentino, mi objetivo en este artículo es describir ciertos efectos subjetivos que produce esta música en la vida de los fans. Con esta exploración busco, por un lado, contribuir al análisis del campo de experiencias en las que se configuran modos de ser joven al interior de las clases populares del mundo contemporáneo. Por otro lado, en un plano analítico, procuro destacar la especificidad de los procesos reflexivos que promueve el encuentro con los objetos de la cultura popular. Como resultado mostraré que esta afición permite procesar subjetivamente diversas experiencias de aflicción, vinculadas con las formas que asume la vida social en estos individuos jóvenes.

Palabras clave: cultura popular, música, escucha activa, juventud (Tesauro de Ciencias Sociales de la Unesco).

\section{The therapeutic dimension of the musical experience: Fanaticism and reflexive work among young fans of a popular Argentine singer}

- Abstract (analytical): Based on ethnographic work carried out between 2008 and 2016 with rock fans from working class sectors, the objective of this article is to describe some of the subjective effects of this music in the lives of fans. This exploration seeks, on the one hand, to contribute to the analysis of experiences in which specific ways of being a young person are formed within the working classes of the contemporary world. On the other hand, at an analytical level, the study aims to demonstrate the specificity of reflexive processes promoted by encounters with the objects of popular culture. As a result, the study shows that through this fanaticism these young people can subjectively process different experiences of their interest in music, which are linked to the social lives of these young people.

Key words: popular culture, music, active listening, youth (Unesco Social Sciences Thesaurus).

Este artículo de investigación científica y tecnológica hace parte de la investigación Música, afición y subjetividad entre seguidores del Indio Solari: un estudio sobre procesos de individuación en sectores populares, presentada por el autor para optar por el título de Doctor en Ciencias Sociales, Universidad Nacional de La Plata, 2015. La misma fue financiada, fundamentalmente, con una beca doctoral del Consejo Nacional de Investigaciones Científicas y Técnicas (Conicet), (contrato 1/4/2009). El trabajo de campo, de tipo etnográfico, se inició el 20 de diciembre de 2008, concluyéndose el 12 de marzo de 2016. Parte del trabajo de campo presentado aquí ha sido realizado junto a Mariana López, Nicolás Welschinger, Jerónimo Pinedo, Mercedes Albo y Ornela Boix, a quienes agradezco especialmente por compartir el material. El mismo tuvo su origen en el marco del Proyecto de investigación colectivo "Los géneros musicales populares: producción, circulación y recepción: identidades sociales y música entre los jóvenes del Gran Buenos Aires" (PICT-2006-02186), dirigido por el Doctor Pablo Semán y financiado por la Agencia Nacional de Promoción Científica y Tecnológica. Área de conocimiento: Sociología. Sub-área: Temas especiales.

** Magíster en Sociología de la Cultura, Universidad Nacional de La Plata, Argentina. Becario posdoctoral Conicet y profesor en la Facultad de Humanidades y Ciencias de la Educación. Orcid: 0000-0001-6856-8514. Índice H5: 3. Correo electrónico: nicolasaliano@hotmail.com 


\section{A dimensão terapêutica da experiência musical: aflição e trabalho reflexivo em jovens fãs de um cantor popular argentino}

- Resumo (analítico): o artigo descreve alguns dos efeitos subjetivos provocados pela música de um cantor de rock argentino na vida de seus fãs oriundos de camadas populares. Para tal intento, foi realizado entre os anos de 2008 e 2016 uma pesquisa etnográfica de seus fãs. A investigação procurou, por um lado, contribuir para a análise do campo de experiências em que "modos de ser jovem" são definidos dentro das classes populares do mundo contemporâneo. Já por outro, num outro nível de reflexão, pretendeu-se realçar a especificidade dos processos reflexivos que promove o encontro com os objetos da cultura popular. Como resultado, entende-se que essa afeição pode processar subjetivamente diferentes experiências de aflição, ligadas às formas que assume a vida social nesses jovens.

Palavras-chave: cultura popular, música, escuta ativa, jovens (Thesaurus de Ciências Sociais da Unesco).

-Introducción. -1. La escena musical: el recital, las banderas y los fans. -2. Más allá de la identificación. -3. Las historias de las banderas: polisemia del mensaje y relatos de la aflicción. -4. Consideraciones finales. -Lista de referencias.

\section{Introducción}

En este artículo indago en la instancia de apropiación de la música en un grupo de individuos jóvenes de sectores populares, aficionados a un cantante de rock argentino. Con base en un trabajo de campo de corte cualitativo con fans del músico Carlos "Indio" Solari una figura que se ha tornado en las últimas décadas uno de los íconos de la cultura popular local-. Exploro en los procesos subjetivos que la afición promueve en la vida de estos sujetos jóvenes. Mostraré aquí que uno de los sentidos centrales de esta afición remite a la posibilidad de elaborar simbólicamente, a través de ella, diversas experiencias de aflicción y sufrimiento presentes en sus biografías.

Visibilizar esta instancia subjetiva que tiene lugar en el encuentro e interacción con la música como objeto cultural, nos permitirá dar cuenta de la especificidad de los efectos sociales que puede "habilitar" la música (De Nora, 2000), al pasar a formar parte de la vida de las personas. En este sentido, enfatizaré aquí en la singularidad de dichos procesos subjetivos en su dimensión afectiva y su conexión con el plano de la sensibilidad, las emociones y la reflexividad. Desde esta perspectiva, se destaca la irreductibilidad de estos procesos a algún tipo de mecanismo social generalizado que oriente las prácticas culturales - como el de la identificación o el de la distinción, según la perspectiva clásica de Bourdieu (1979/2012) . En su lugar, se busca situar el análisis en un plano más próximo al de la densidad de la experiencia que tiene lugar en el encuentro con los recursos culturales.

Dicha indagación ofrece, asimismo, un fecundo campo de exploración de los modos en que se configura la experiencia juvenil entre los sectores populares urbanos contemporáneos ${ }^{1}$. La exploración ilumina dinámicas culturales a partir de las cuales algunos procesos considerados "estructurales" (crisis económicas, precarización laboral, exposición a diversas formas de riesgo) son elaborados simbólicamente y tramitados subjetivamente, delineando un modo de experimentar, en el mundo popular, una condición juvenil específica.

En este punto, Chaves (2017) ha advertido recientemente, en un balance sobre los estudios de juventud en el ámbito latinoamericano, sobre la importancia de elaborar enfoques que recuperen esta dimensión de la vida

1 Asimismo, en el reciente trabajo de Di Leo y Camarotti (2017) se abordan dimensiones ligadas al plano de las emociones, la afectividad y el procesamiento de diversas instancias de violencia y sufrimiento para caracterizar las biografías de jóvenes de sectores populares en la Argentina, cuyos resultados dialogan de manera directa con los que aquí presento. 
social —ligada a las emociones, el sentir y la sensibilidad - para abordar la experiencia juvenil. Al respecto, Chaves sostiene que especializaciones disciplinares como la antropología del cuerpo, de las emociones y de la música "están intentando y consiguieron avanzar teórica y metodológicamente sobre este punto, en particular cuando se trata de estudios sobre el procesamiento sociocultural de los dolores, padecimientos y placeres" ( $p$. 7). En línea con este planteamiento, nutro el presente artículo de esos desarrollos, a la vez que pretendo contribuir en la consolidación de los vasos comunicantes entre ellos.

En vista de estos propósitos, organizo el argumento en cuatro momentos. En la primera sección recupero y contextualizo algunos rasgos de la escena musical de la cual participan activamente estas personas aficionadas. En la segunda sección abordo el modo en el que, de un modo general, se ha tendido a concebir los efectos subjetivos de la música - en torno al proceso simbólico de la identificación-, y destaco la importancia de trascender esta mirada. En la tercera sección, a partir de presentar los relatos que se activan al momento de contar las historias de sus banderas, reconstruyo los procesos subjetivos con lo que esta práctica se conecta en la vida de los sujetos jóvenes.

\section{La escena musical: el recital, las banderas y los fans}

Carlos "Indio" Solari cuenta con una extensa trayectoria dentro del rock argentino. Este artista formó parte de una de las bandas centrales del movimiento del rock nacional de las décadas de los ochenta y noventa - la agrupación Patricio Rey y sus Redonditos de Ricota-. En este sentido, como algunos analistas han destacado (Guerrero, 2005; Semán, 2006), Patricio Rey fue una banda que tuvo sus orígenes dentro de una experiencia estética y social acotada a capas específicas de las clases medias que, sin embargo, en la década de los noventa incorporó un nuevo público, proveniente de sectores populares de las periferias urbanas. Un proceso por el cual la banda se tornó masiva y fue apropiada por este público (Semán, 2006), imprimiendo nuevas prácticas y representaciones a la escena. Este fenómeno asumió dimensiones inéditas en las décadas posteriores, bajo la figura de Solari como solista, una vez disuelta la banda en 2001. En este cuadro, sus recitales frecuentemente referidos por sus aficionados como "misa ricotera"- se convirtieron en eventos multitudinarios, objeto de una creciente ritualización, y la propia figura de Solari pasó a ser un objeto de culto al interactuar con un campo de experiencias ligado al mundo popular.

En esta clave, una serie de trabajos han analizado algunos de los efectos de la incorporación, a partir de la década de los noventa, de los sectores populares al rock. Entre las principales dimensiones estudiadas se señaló la conformación de una nueva relación entre emisor y receptor, en la que el público gana centralidad: una contraescena activa (Semán, 2006), un proceso de carnavalización del rock (Alabarces, 2008). A la vez, se describió un proceso de "futbolización" del género (Alabarces, 2008; Semán, 2006), a partir del cual se comenzó a estudiar algunas prácticas y valores transferidos desde las tribunas de fútbol: la elaboración y uso de banderas (Aliano, López, Pinedo, Stefoni, \& Welschinger, 2010) y el "aguante" como categoría física y moral entre ellas (Alabarces \& Rodríguez, 1996; Garriga \& Salerno, 2008). En este cuadro, problematizaré aquí la instancia de interacción y apropiación de la música en los fans de Solari, en la escena que se fue conformando más recientemente. Esta indagación será realizada a partir de recuperar como objeto de análisis la práctica de la producción de "banderas" que los fans elaboran para su uso en el contexto de los recitales.

Estas banderas se caracterizan por ser producciones que combinan dos elementos: la elección de una frase tomada de las letras de las canciones, junto con una o varias imágenes provenientes de la gráfica de los discos o de fotografías de los músicos. ${ }^{2} \mathrm{La}$ indagación en

2 Estos elementos, dibujados y pintados, además suelen ir acompañados con los nombres de las personas que los realizaron, de seres a los que por algún motivo se quiere rendir homenaje o de la zona de procedencia de los individuos fans. Para una mayor 
torno al arco de relatos que se abren al momento de explicar el fanatismo e inscribirlo en las banderas, me permitió recuperar dimensiones de la experiencia cotidiana de estas personas, que llevan sus vivencias junto con las banderas a la escena del recital. Los individuos entrevistados son en su mayoría jóvenes que nacieron entre las décadas de los ochenta y comienzos de los noventa, de sectores urbanos periféricos, con un nivel de escolaridad bajo y con empleos precarios.

Al abordar sus historias se advierte una elaboración de relatos ${ }^{3}$ que movilizan diversos motivos de carácter personal: la vida sentimental y amorosa, el sufrimiento, la amistad, la familia o la muerte de los seres próximos. En este artículo analizaré un tipo de relato presente de manera recurrente entre las "historias de banderas", que se destaca tanto por el grado de implicación subjetiva con el que es asumido por los fans, como por poner en superficie un efecto específico de la música sobre sus biografías. Se trata de los relatos sobre distintas instancias de aflicción que experimentan estos individuos jóvenes, y del lugar terapéutico que el vínculo con la música produce para mitigar estas situaciones.

Situados en este plano, cabe un rodeo preliminar para encuadrar este análisis en el contexto más amplio de exploraciones que se han abocado a estudiar recientemente la relación entre música y subjetividad.

\section{Más allá de la identificación como operación simbólica}

Como acabo de señalar, se parte aquí de destacar la especificidad de los efectos

caracterización de esta práctica el lector o lectora puede remitirse a Aliano et al. (2010) y Aliano (2015)

3 Elijo hablar aquí de relatos, ya que se trata de construcciones discursivas que mantienen cierta estabilidad como forma a partir de la cual se generan discursos sobre la práctica. En este sentido, se aproximan a la noción de narrativa (Ricoeur, 1990/1996), ya que en muchos de ellos hay un compromiso subjetivo entre lo narrado y la propia biografía. Sin embargo, quiero preservar la noción de relato porque - en igual sentido que en lo observado por Kessler (2009, p. 107) para el caso de los "relatos sobre la inseguridad"- muchos de estos no se caracterizan por desplegar un esquema argumental en el que la temporalidad - elemento central de la noción de narrativa - sea el eje organizador decisivo de la propia existencia en el flujo del tiempo. subjetivos que puede promover el encuentro con la música. En este punto, el análisis se inscribe en aquellos desarrollos que han concebido la operación de la escucha musical como una instancia activa de producción de sentidos sociales. Dicho planteamiento emergió como un cuestionamiento a las visiones que subrayaban la pasividad de la recepción musical de los productos de la cultura de masas: los análisis orientados por perspectivas como la de Adorno y Horkheimer (1944/1969) en torno a los efectos de la industria cultural. Pero, de forma simultánea, el planteamiento de la productividad de sentidos en la escucha también se constituyó frente a perspectivas preocupadas por identificar una correspondencia entre grupos sociales y objetos culturales, bajo algún tipo de "homología estructural" entre ambos (Bourdieu, 1979/2012; Hebdige, 1979/2004). Bajo este tipo de enfoque, los objetos y gustos musicales específicos se conectarían con colectivos sociales definidos y ya constituidos, de modo que una determinada música representaría o distinguiría a ese grupo.

En este contexto es que autores como Vila (1996) y Frith (1996/2003) destacaron, en respuesta a análisis frankfurtianos, la productividad de la escucha como parte de un proceso de recepción activa de los sujetos. De modo complementario, en respuesta a las perspectivas homológicas, pusieron de relieve el poder de la música como recurso para elaborar identificaciones: advirtieron que las identidades no estaban dadas en un plano social previo que se reflejaba en la música, sino que las mismas emergían en la experiencia misma de los usos musicales, siendo dicha instancia particularmente productiva para la elaboración de grupalidades e identidades. Con ello se abrió una senda al análisis de los efectos sociales específicos de la música, más allá de concebirla como reflejo, traducción o expresión de procesos que ocurrían "en otra parte".

Este movimiento orientó diversas exploraciones que - muchas veces tamizadas con categorías como la de bandas juveniles o tribus urbanas - procuraron dar cuenta del carácter performativo de identidades juveniles 
a partir de diversos consumos musicales ${ }^{4}$. Sin embargo, a modo de balance, este giro se mantuvo en una visión de la recepción musical limitada a la operación de la identificación, como si las personas — según destaca Semán (2011) — solo pudieran identificarse a partir del uso de la música ${ }^{5}$. De manera que aún resta profundizar, a través de exploraciones empíricas concretas, sobre otros efectos subjetivos que promueve el encuentro con los objetos musicales, más allá de la identificación como operación simbólica generalizada. Esta observación, de un modo simétrico, ha sido subrayada en desarrollos recientes para fenómenos próximos al de la escucha musical, como el caso de la recepción literaria (Lahire, 1998/2004; Papalini, 2016; Petit, 2001).

Con la exploración que presento a continuación busco contribuir a este debate, inscribiendo algunas de las especificidades de los procesos que habilita (De Nora, 2000) el encuentro con un objeto musical concreto. En el contexto argentino, una serie de trabajos recientes han aportado a este movimiento de singularización de los efectos que produce la música. Desde una perspectiva etnográfica, trabajos recientes sobre el tango bailado en Buenos Aires (Carozzi, 2015), sobre la escena de la música electrónica (Gallo, 2011; Lenarduzzi, 2016), sobre el baile del cuarteto (Blázquez, 2014), sobre la escucha de cumbia villera (Semán \& Vila, 2011) o sobre fans del cantante de música romántica Ricardo Arjona (Spataro, 2013), entre los más destacados, han atendido al modo en que la música se vuelve un recurso reflexivo específico sobre el yo, que configura dimensiones de la agencia social, de las emociones y del cuerpo. Inscrita en este movimiento, la indagación que se despliega a continuación muestra que los efectos reflexivos que puede desencadenar la vinculación con un objeto musical dinamizan procesos subjetivos a la vez más complejos y más específicos que la

4 En Aliano (2010) presento un recorrido pormenorizado a través de esta literatura, haciendo especial hincapié en el caso argentino.

5 Al respecto, Semán (2011, p. 3) puntualiza: “en la relación con la música hay más variedad de la que se explora bajo el conceptoresumen de 'identificación', o sea, se comprimen las razones por las que se supone que un 'joven' se aproxima a la música”. operación de identificación. Los mismos aluden a una dimensión terapéutica y de reconstrucción subjetiva asociada a la experiencia musical, de la que busco dar cuenta.

\section{Las historias de las banderas: polisemia del mensaje y relatos de la aflicción}

En los relatos que se despliegan para narrar la historia de la bandera suelen aparecer motivos vinculados a episodios traumáticos o momentos de crisis en la vida de los fans o en la de sus vínculos próximos. Estos relatos tienen la aflicción como común denominador de diversas experiencias de alteración afectiva, siendo la muerte de un amigo, la experiencia de la pobreza y el consumo de drogas los motivos más frecuentes. Estos motivos son movilizados desde la interpretación de las imágenes y de los fragmentos de las letras de las canciones que se seleccionan para pintar en las banderas.

La presencia de este tipo de operación selectiva e interpretativa se vincula con uno de los rasgos característicos de las líricas de las canciones de Solari: su pretendido carácter críptico o no-literal. Dicho carácter promueve un tipo de operación específica: una escucha ligada a un ejercicio de decodificación del mensaje transmitido por el artista y que suscita diversas interpretaciones personales.

El carácter polisémico de las letras, como rasgo característico de este objeto musical $-\mathrm{y}$ dimensión "habilitante" del mismo-, estimula un proceso de dotación de sentidos personales que son develados por el mensaje. Se trata de una dimensión que Carozzi (1993) ha referido como "la construcción social del efecto mágico" (p. 68). Al analizar la situación de consulta en los templos umbanda, la autora encuentra que la adivinación de aspectos no revelados del consultante depende de un discurso potencialmente polisémico: un discurso que la persona consultante "llena de significados a partir del conocimiento que posee de sí misma" (Carozzi, 1993, p. 73).

De un modo similar a lo observado por Carozzi, para esta situación los propios artistas que intervinieron en Patricio Rey —o "Los Redondos", según una denominación frecuente 
de sus fans - han fomentado un tipo de escucha interpretativa anclada en el carácter polisémico de las letras. Así la caracteriza Solari: "No creo en las letras que son explícitas, creemos en la sugestión, la fantasía y en la composición. No me interesan como panfleto, hay un misterio que obra de una manera oracular" (Guerrero, 2005 , p. 145). Se trata de un tipo de operación que ha pasado a formar parte del sentido de uso del objeto. Rocambole —uno de los artistas que estuvo ligado a la producción estética de la banda- lo describe de este modo: "lo que pasa es que el mensaje, si es que hay algún mensaje, es tan amplio como la Biblia: cada persona encuentra en ese mensaje algo que le está destinado" (Guerrero, 2005, p. 156). Estas consideraciones, en suma, aluden a un lugar común que todos los fans de Solari asumen y destacan: la búsqueda de una interpretación del mensaje.

En esta clave, frases recurrentes como "mi único héroe en este lío" - de una lírica de Patricio Rey - o "nadie es capaz de borrar mi recuerdo, nadie es capaz de matarte en mi alma" - de una de las canciones de Solarison apropiadas como frases de las banderas desde diversos relatos biográficos. En líneas generales, a partir de estas frases se produce el relato de historias sobre experiencias vividas intensamente (los contenidos son variados, pero suelen tener en común el ser vividos traumáticamente), que se asocian y articulan con las experiencias producidas en la escucha musical o en la participación en la escena. En este cuadro, se identifica en los relatos dos tipos de acentuaciones al momento de tematizar estas experiencias: por un lado, aquellas que ponen el foco en inscribir situaciones dolorosas y de aflicción en el marco grupal de relaciones: amigos, o familiares que homenajean o conmemoran a seres queridos que han sufrido diversos problemas o han fallecido; por otro, historias en las que el acento se desplaza hacia la propia persona como objeto de aflicción y búsqueda de sentidos.

\subsection{Inscribir la aflicción de/con los pares.}

Me detendré en este punto en el primer tipo de relato. La historia de la bandera que exhibe
Daniel, un fanático de la localidad de San Justo, permite un acercamiento inicial al mismo. Daniel realizó la bandera junto con tres amigos en el año 2000 y cuenta que, una vez realizada, otros amigos fueron agregando sus firmas "al trapo", para asistir en grupo a los recitales. Sin embargo, una de las jóvenes que formaba parte del grupo murió tras un accidente en moto, motivo por el cual el grupo de jóvenes decidió entregarle la bandera a su madre, como recuerdo de la hija. Sin embargo, Daniel y sus amigos le prometieron a la madre que cada vez que Solari hiciera una presentación irían a buscar la bandera, para llevarla al recital. Daniel explica: "la bandera, cuando el Indio toque, va a estar; yo a la madre de la piba le llevé varias fotos donde estaba la piba con la bandera y todos los pibes (...); relloraba, estaba recontenta". Mientras cuenta esa historia, Daniel aclara que él y su grupo de amigos y amigas además son devotos del Gauchito Gil. Por eso Daniel y sus amigos van todo primero de enero en bicicleta hasta Luján: "hace cinco años que hacemos estos viajes, lo del gauchito y lo del Indio es lo mismo, en el sentimiento, en la fiesta".

El relato de Daniel visibiliza la función terapéutica que tiene la práctica que han establecido, tanto para el grupo de amigos y amigas, como para la madre de la joven fallecida. Este uso de la bandera los ayuda a conmemorarla, a procesar la pérdida y a aliviar la angustia. Y, en ese proceso, Daniel compara la experiencia del recital con la de su devoción por una figura de la religiosidad popular, como planos conectados de una experiencia extraordinaria.

Elaboraciones simbólicas similares se observan en diferentes historias que, sin embargo, comparten los motivos. En otro caso, la historia de la bandera se vincula con mantener viva la memoria de un joven desaparecido. Un fan me cuenta que realizó la bandera seleccionando la frase "de la nada a la gloria me voy" (de una de las canciones de "Los Redondos") en homenaje a Daniel Solano, un trabajador rural de Salta, que fue visto por última vez con vida en la ciudad de ChoeleChoel, su lugar de origen ${ }^{6}$.

6 Todas las fotografías que se incluyen a continuación son de mi autoría. 


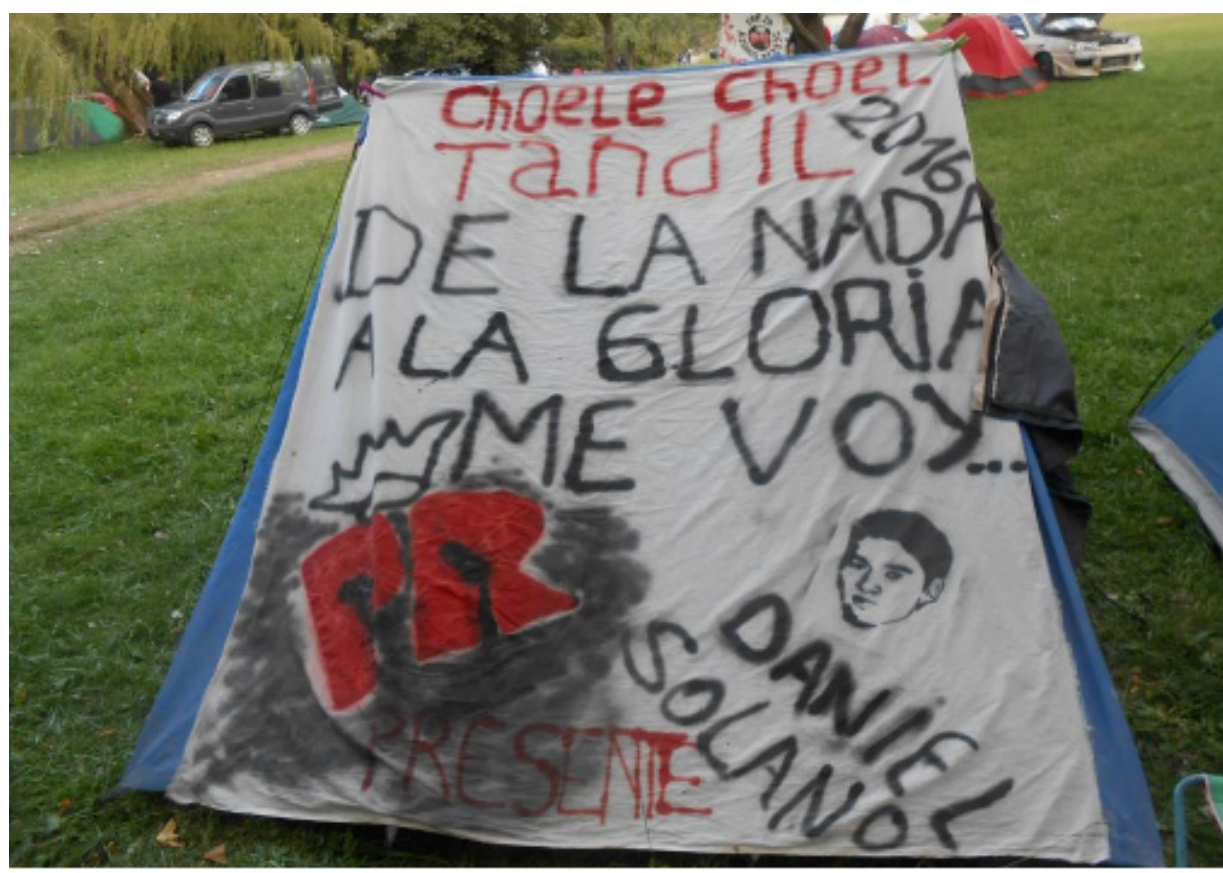

Figura 1. "De la nada a la gloria me voy. Daniel Solano presente" (Tandil, 2016)

Asimismo, en algunos casos se busca conmemorar $u$ homenajear momentos compartidos escuchando o asistiendo a los recitales de "Los Redondos" con seres que ya no están, o encontrando en el momento del recital una ocasión especial de expresión de sentimientos de afecto y homenaje hacia esos seres queridos. "Usé la frase 'nadie es capaz de borrar tu recuerdo' porque hace un año y medio murió mi vieja atropellada; por eso le puse eso", explica un joven de la ciudad de Salta. "Me va alumbrando la luz de los que no respiran" se lee en otra bandera, donde un seguidor de Santiago del Estero, según explica, dibujó la imagen del Indio junto a la de su madre fallecida para conmemorarla.

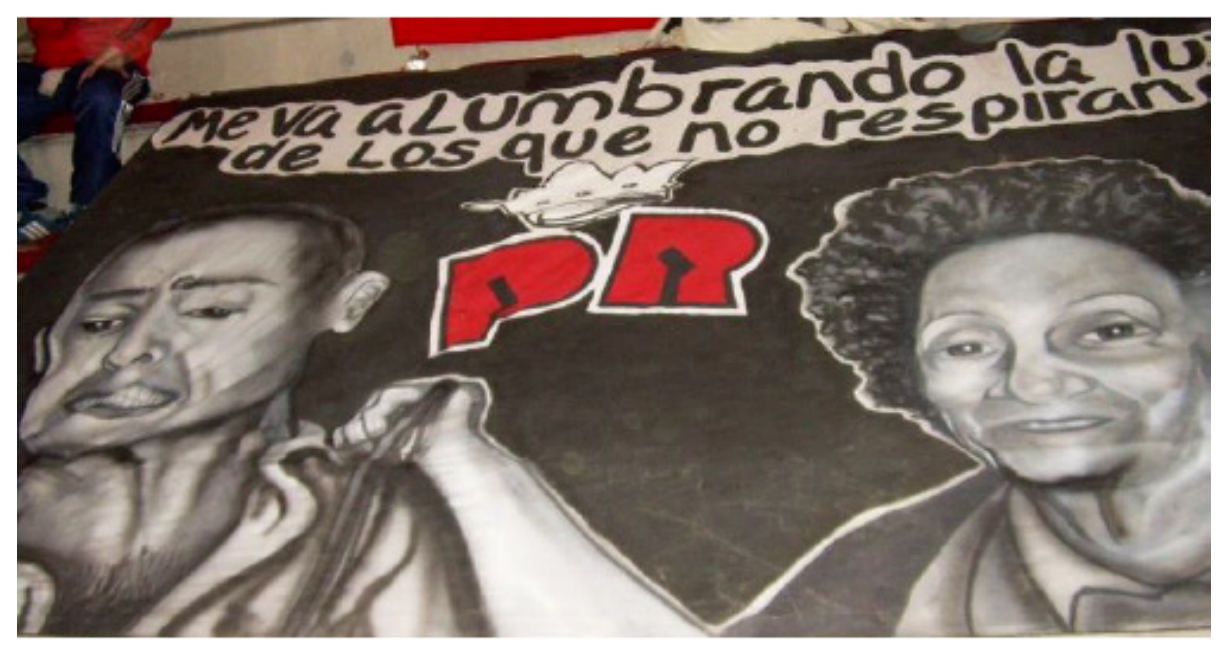

Figura 2. "Me va alumbrando la luz de los que no respiran" (Salta, 2009) 
La práctica de hacer y llevar una bandera se inviste afectivamente: se trata de exponerla en ese momento extraordinario de la experiencia vital que es ir al recital, para homenajear o conmemorar a un ser querido o dar testimonio de un hecho. Cacho, de José C. Paz, cuenta: "a la bandera la hice en conmemoración de mi hermano, que murió de un paro cardíaco". Cacho lee la frase de la bandera: "para el Moro que está en el cielo, dedícale un rock and roll"; $\mathrm{y}$, mientras narra emocionado la historia, cada vez que menciona a su hermano, sus amigos le dan consuelo.

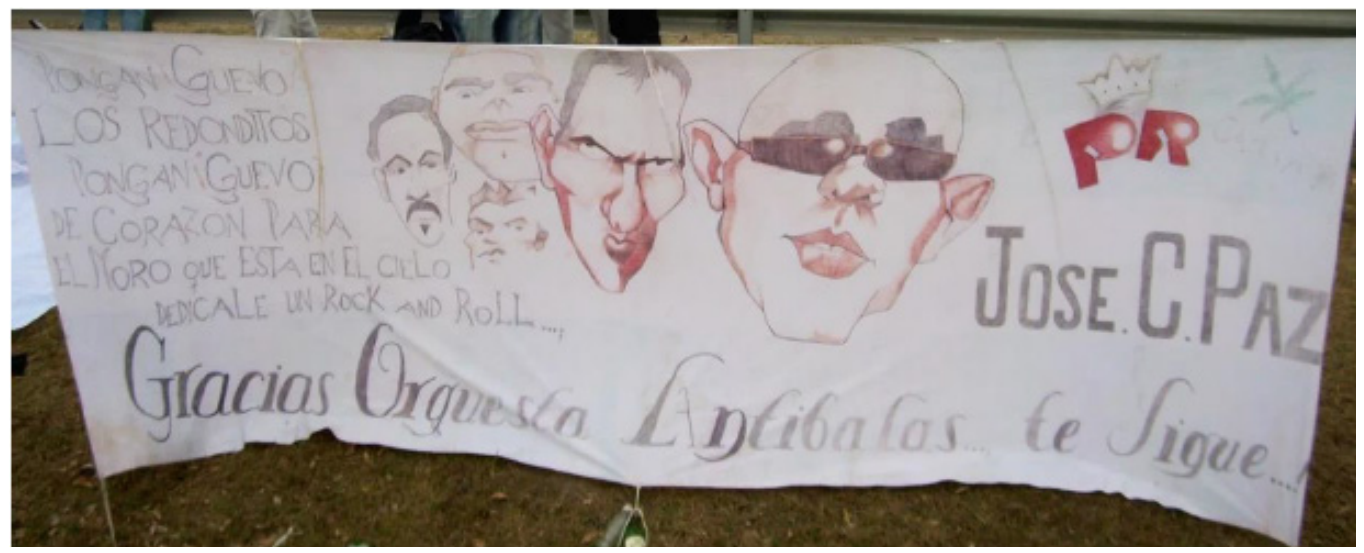

Figura 3. "Pongan guevo Los Redonditos, pongan guevo de corazón para el moro que está en el cielo, dedícale un rock and roll. Gracias orquesta antibalas te sigue”. José C. Paz (Salta, 2009)

Asimismo, en esta línea de relatos, un grupo de amigos de la ciudad de Lincoln seleccionó la frase "pensando en vos siempre, siempre extrañándote", de una de las canciones de Solari, para estampar en su bandera. Los jóvenes explican que con ello buscaron evocar y mantener en la memoria a uno de los amigos que se suicidó.

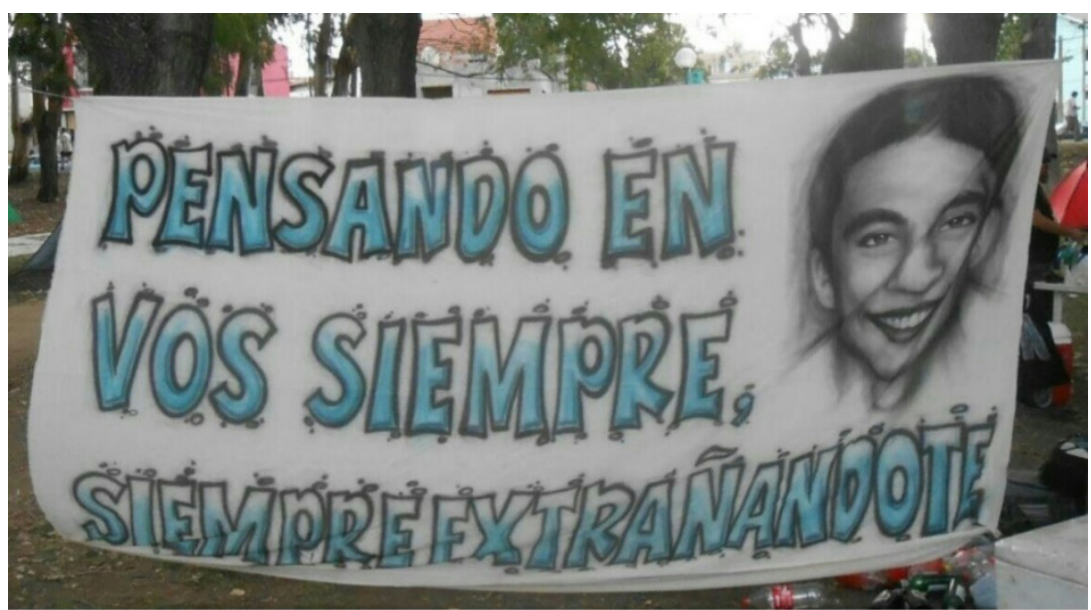

Figura 4. "Pensando en vos siempre, siempre extrañándote” (Tandil, 2016)

Tras los casos recuperados encontramos que la presencia de motivos ligados a accidentes o a muertes jóvenes (absurdas o inesperadas) atraviesa varios de los relatos. Esta presencia recurrente da cuenta de una inscripción simbólica 
de los efectos de la exposición a diversas formas de una precariedad social que responden a procesos sociales macro: crisis económicas, flexibilización laboral o restricciones al acceso a la salud. En esta línea, algunos testimonios adicionales nos permitirán terminar de iluminar esta dinámica simbólica ligada a procesar subjetivamente diversas aflicciones asociadas a situaciones de vulnerabilidad.

Un grupo de jóvenes de la ciudad de San Martín explica que la bandera que portan es una forma de tener presente y homenajear al amigo ausente. "Es la primera vez que la traemos nosotros — cuentan- porque siempre vino el otro muchacho. Tuvimos la posibilidad de llevarlo a Córdoba, después no lo pudimos llevar más, porque está mal, no está bien". Los jóvenes explican las causas de la ausencia de su amigo: "se colgó en un poste de luz, quedó electrocutado ahí y cayó al piso. Está mal, no se acuerda. El chabón es un pibe que fue a [el estadio] Obras, a todos lados. Un chabón que nos siguió a todos lados." El accidente de este fan conduce a sus amigos a homenajearlo, volviéndolo a la presencia al portar su bandera: "la bandera es importante por todo eso, porque si yo no vengo la bandera no viene, y la bandera está porque yo estoy."

En otra de las historias se replica el mismo sentimiento: evocar y homenajear al amigo ausente que cayó en desgracia. Rodrigo (Berazategui, 29 años) señala: "esta bandera la dibujó un chico que tuvo una desgracia; tuvo una desgracia con la familia", y explica lo sucedido: "el chico se estaba por casar, se iba a entregar las invitaciones de casamiento a una familia en Mar del Plata. Iba con un [Peugeot] 504, se le cruzó una liebre y por esquivar la liebre se fue para abajo del campo, descarriló. Y falleció la madre, el padre y la señora con la que se iba a casar, y él quedó inválido." El joven que relata lo sucedido explica que intentó llevar a su amigo al recital, con la silla de ruedas, pero no pudo convencerlo. Por ello es que, como forma de homenaje, le prometió exponer su bandera en la previa al show: "el trapo este lo había hecho él —concluye-, ahí le puso "Cristian 2008'. Lamentablemente no pudo venir.”

Igualmente, se advierte la intención de homenajear al amigo muerto en este otro relato (Lucas, 20 años, Mendoza):

El chabón tenía diabetes. Se fue a Buenos Aires y se llevó las inyecciones y todo eso. Entonces salió a bailar, le agarró un ataque y ahí quedó. Estaba con una chabona que ni lo conocía a él (...). Entonces falleció allá. Pero estoy contento porque está con su padre, que también falleció por lo mismo. Y bueno, le pusimos "vamos a extrañar el botiquín" por todas las fiestas que pasaba con nosotros. Nosotros íbamos a los recitales con él, viste (...). Cuando vino por primera vez acá a Mendoza el Indio ¿viste?, vinimos con él, y sacamos una banda de fotos, y después de eso fuimos a Gualeguaychú (Lucas, comunicación personal, 13 de diciembre de 2014).

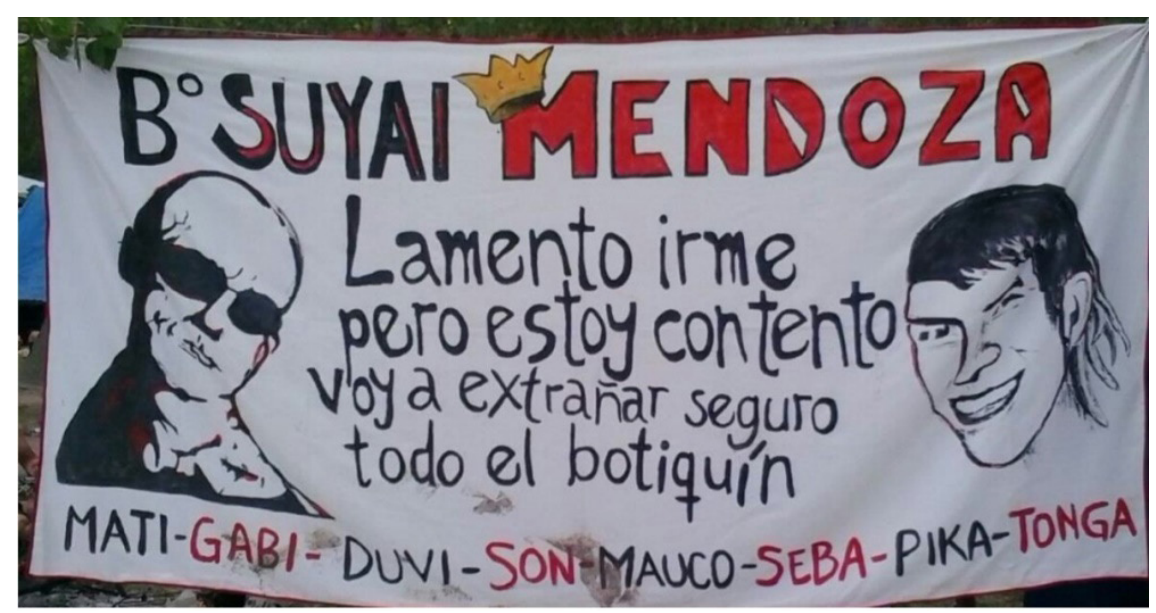

Figura 5. "Lamento irme pero estoy contento. Voy a extrañar seguro todo el botiquín” (Mendoza, 2014) 
En suma, el tipo de relato que he presentado hasta aquí en varias "historias de banderas" elabora una experiencia social con rasgos recurrentes y compartidos. En este plano se advierte que, como sostiene Kessler (2013), la muerte se introduce dentro del campo de experiencias posibles entre estos jóvenes de clases populares. Destacando esta dimensión, Kessler observa que, a diferencia de décadas pasadas, la muerte se ha vuelto una presencia próxima y visible en los relatos de los jóvenes de sectores populares: "muertos por la policía, por otros jóvenes, pero también por accidentes de tránsito, por HIV-sida, por causas poco claras, los relatos del barrio están poblados de jóvenes fallecidos durante los últimos quince años" (Kessler, 2013, pp. 153-154). El tipo de relato presentado, en línea con las observaciones de Kessler, pone en escena un proceso específico: la sedimentación reciente de formas de riesgo social, emergentes de transformaciones societales de carácter estructural. En este marco, los efectos de la exposición a estas formas no son naturalizados pero, como observamos, comienzan a tener relatos y guiones culturales para su tramitación. Por ello, más allá de la diversidad de contenidos con que se construyen las historias, advertimos que estas tienen dos rasgos recurrentes: la intensión de dar sentido a episodios vividos traumáticamente - que se presentan como absurdos o inexplicables-y la búsqueda de un consuelo, que cumple una función terapéutica.

\subsection{La propia persona en el centro del trabajo reflexivo.}

En otros casos, el acento de las historias está puesto en la propia persona como objeto de sufrimiento y reflexión. En estos relatos ya no se trata de procesar experiencias de aflicción en el seno de relaciones grupales - a partir de homenajear a seres que han sufrido diversos problemas - sino de elaborar experiencias dolorosas que tienen como centro la propia biografía y que motivan una búsqueda de sentidos. En esta línea, por ejemplo, el relato de un fan en torno a los motivos de la realización de su bandera condensa esta acentuación: "esto me explica. Esto es mi pobreza. Si yo pierdo este trapo mi pobreza se va", afirma Fabián, mostrando la intensa conexión biográfica con su bandera. Me detendré en una última historia que permitirá comprender este tipo de operación simbólica, asociada a un trabajo personal y reflexivo sobre sí mismo.

La historia se destaca por la carga emotiva que deposita el fanático en el relato, que lo tiene como centro de un balance introspectivo. Antes de contarme qué es lo que lo llevó a hacer la bandera, el joven que la realizó —Adrián (Castelar, 25 años) — me aclara: "me vas a hacer poner triste". La bandera tiene el dibujo de la cara de una niña y su rostro está rodeado por un aura dorada. Debajo de la imagen está escrito su nombre: "Abril", junto al símbolo de Patricio Rey y las palabras "Córdoba, Tandil" - los lugares en los que estuvo presente anteriormente la bandera-. Como leyenda principal se lee: "Mi único héroe en este lío".

Contar la historia de esa bandera conduce a Adrián a relatarme una pasada relación de pareja: "yo tenía veinte años, hoy en día tengo veinticinco. Yo conocí a una chica y empiezo a tener una amistad con ella y luego empiezo a salir con ella". Esta joven tenía una hija de seis meses - Abril, la niña que aparece dibujada en la bandera - a la cual Adrián acoge como si fuera su hija: "para mí va a ser mi hija siempre - explica - la quiero como si fuese mía, mi corazón es de ella; o sea, es la sensación más profunda y más linda que tuve en la vida". Esa relación terminó con la ruptura del vínculo y la separación dolorosa respecto a Abril, la pequeña hija de su pareja. Adrián relata emocionado cómo construyó un lazo afectivo con la niña y expresa con la voz quebrada la importancia que mantuvo ese vínculo en su vida, una vez que la relación de pareja concluyó: "no hay día y no hay noche que yo no me acuerde, me siente en la cama y no me rompa la cabeza, porque tengo todos los dibujos de ella, todas las cosas", cuenta. La de Adrián es la historia de una separación traumática, atravesada por el sentimiento de pérdida del vínculo con esa niña. El joven reconstruye emotivamente ese vínculo a partir de la evocación, al recordar, entre lágrimas, esos momentos en que le hacía escuchar su música: "Yo le decía: "vamos a escuchar a Los Redondos', 'si papito' — me 
decía- y yo jugaba con ella y hacía un picnic y mirábamos Barbie". En la historia de Adrián, de una manera elocuente, el hecho de hacer una bandera es un modo de procesar ese sentimiento de pérdida, haciendo posible su simbolización: Hoy en día a mi primo le digo que esta bandera es el último recital que va a tener. Le digo: voy a esperar diez años, diez años; la nena va a cumplir quince años y se la voy a regalar. Y la voy a encontrar, porque yo te puedo asegurar que yo la voy a encontrar. Esta bandera fue a Córdoba, Tandil, San Luís, y se va a guardar diez años, y cuando ella cumpla quince se la voy a dar, pero porque yo me conozco mi corazón, yo sé lo que soy, ¿entendés?, y de ahí para adelante. Si vos mirás para atrás cuando caminás para adelante, te tropezás. No puedo mirar más para atrás. Pero te lo juro por Dios, que yo he estado mal mucho tiempo por muchas cosas, pero no hay día que yo apoye la cabeza y no se me rompa la cabeza. (Adrián, comunicación personal, 20 de diciembre de 2008).

El fracaso de la pareja como acontecimiento significativo suscita en Adrián la reflexividad, conduciéndolo a un trabajo introspectivo. Adrián expone el proceso de desestabilización del soporte que, como refugio afectivo (Sustas \& Touris, 2013), representaba la pareja y su hija, y apela a la música y a la bandera como recursos para procesar la ruptura y mitigar la angustia producida. Se observa aquí, en línea con lo señalado en trabajos como el de Spataro (2013) con mujeres fans de Arjona, cómo las situaciones de aflicción o crisis pueden desencadenar un trabajo personal y reflexivo de búsqueda de sentidos a partir de la experiencia musical. ${ }^{7}$ Así intenta explicarlo Adrián, para quien el Indio es como un padre, y la música de "Los Redondos" se conecta con su vida y su amor por la hija de su ex pareja, a la que ya no puede ver:

Yo escucho Los Redondos desde los trece años; me está llenando la cabeza de humo hace... tengo veinticinco, ¿cuántos serían? Diecisiete años. Es como un padre. Viste cuando vos decís loco ¿yo estoy loco? Y no, no estoy loco, mirá

7 En esta línea, asimismo, Da Matta (2002, p. 44) ha observado que cuando los ritos son momentos individualizadores, suelen estar volcados a la resolución de crisis de vida o a momentos de aflicción. lo que cantan, se entiende. Es como algo que se conecta. Y realmente, mirando toda mi vida en sí, yo nunca tuve tal sentimiento ni nadie me movió tanto el piso como esta criatura, ¿entendés? Y es como lo ves, es "mi única héroe en este lío." (...) [A la bandera] yo la cuelgo, no para vos, no para vos [va señalando a gente alrededor], yo la cuelgo para mí. (Adrián, comunicación personal, 20 de diciembre de 2008).

"Yo la cuelgo para mí", dice Adrián emocionado, para explicar el motivo profundamente personal de su bandera. Adrián en su relato tramita un momento traumático a partir de la música del Indio: "es como algo que se conecta", explica, y eso que "conecta" de la música le permite dar sentido a una experiencia individual: un momento que lo pone a prueba y a partir del cual Adrián responde apelando a un trabajo centrado sobre su yo.

\subsection{Una clave ético-práctica de apropiación.}

¿Cómo es apropiada esta música por los fans?, ¿qué efectos tiene sobre sus vidas? En estos relatos se advierte una clave de interpretación particular, en la que el mensaje es apropiado y significado a partir de experiencias cotidianas y problemáticas recurrentes. Lahire (1998/2004) define este tipo de apropiación, orientada por las motivaciones de la propia experiencia, como ético-práctica. Desde esta orientación, la incertidumbre respecto a un futuro incierto, la enfermedad o la muerte, los estados de angustia o tristeza, se presentan como temáticas que movilizan el mensaje del Indio. Este artefacto cultural, de este modo, pone en funcionamiento mecanismos de interpretación que permiten "hacer trabajar, de manera imaginaria, los esquemas de la propia experiencia" (Lahire, 1998/2004, p. 137). A través de ello los fans procuran formas de evasión, de preparación para situaciones difíciles, o buscan otorgar sentido a una realidad dolorosa y sobreponerse a ella.

A la luz de estos relatos, en suma, se visualiza un trabajo de simbolización que no es reductible al tópico de la identificación (Petit, 2001) con determinados contenidos o 
categorías de pertenencia, abarcando en cambio un proceso más complejo. En las historias es posible encontrar otra dimensión que habilita la música y la figura de Solari afectivamente investida: superar una muerte dolorosa — los casos de Cacho, Rodrigo o Lucas-, elaborar un sentido sobre la experiencia de la pobreza, sobre las etapas del ciclo vital o sobre una separación dolorosa - la historia de Adrián-, para dar energías, consuelo o fuerzas a un yo que es fuente de aflicción, y transportarse así a otro lugar. En todos estos casos el relato, elaborado a partir de contenidos diversos, tiene sin embargo una lógica similar: dar sentido a episodios traumáticos y poder tramitar los sentimientos de aflicción que atraviesan los sujetos. La música, por haber formado parte de experiencias ligadas a homenajear a esos seres o a uno mismo, se constituye en un recurso para tramitar, evocar o superar simbólicamente esas vivencias, y las banderas son la superficie de inscripción de ese trabajo.

En este sentido, la recurrente manifestación de estos relatos que presentan ciertos dramas de la existencia, apropiándose de la música en un rol terapéutico, estaría confirmando la hipótesis presentada por Lahire (1998/2004, p. 137) para el caso de la experiencia de la lectura $-\mathrm{y}$ que se puede extender aquí para la experiencia de la escucha-. Conforme esta perspectiva, las situaciones de desajuste que provocan crisis más o menos fuertes (la muerte de un ser querido, una separación dolorosa) y algunos momentos cumbre en el ciclo de la vida (periodo de la adolescencia, aprendizaje del rol de madre o de padre, etc.), constituyen ocasiones particularmente propicias para este tipo de trabajo simbólico.

A la vez, como se destacó previamente, la recurrencia de esta clase de relatos constituye un indicador de ciertas condiciones sociales en las que se configura y tramita subjetivamente la experiencia de la aflicción. La música, el contenido de sus líricas y las experiencias que se ligan a su escucha, ofrecen aquí una forma de simbolizar la presencia de la sociedad en las biografías. En varios de estos casos se trata de la exposición a riesgos y peligros vinculados a procesos que afectan de manera más incisiva a las clases populares: la precarización laboral, las limitaciones en el acceso a la salud o a las protecciones laborales, las malas condiciones habitacionales ${ }^{8}$. Estas situaciones generales se traducen en el plano de la experiencia subjetiva a través de sentimientos de angustia o incertidumbre, que conducen a los fans a vivir diversos acontecimientos de su entorno como pruebas existenciales (Martuccelli \& Araujo, 2010) ${ }^{9}$. Con diferentes matices y acentos, los relatos hacen referencia a este nivel, dando cuenta, en cada caso, de la acción restauradora que puede producir la experiencia musical frente a las pruebas que se presentan.

\section{Consideraciones finales}

A la luz de las descripciones que los individuos entrevistados realizan en torno a la confección de sus banderas es posible observar una apropiación de los materiales utilizados dibujos, imágenes, líricas - de acuerdo con una experiencia social que traen a su relación con la música y procesan en un trabajo subjetivo. La sociabilidad barrial, la exposición a diversas formas de la precariedad que predispone a sufrir accidentes, enfermedades, muertes de seres queridos (motivos todos ellos que se incorporan en el campo de experiencias posibles en el mundo popular), son elementos articulados simbólicamente en las banderas y en sus historias. A través de ellas podemos reconstruir el modo en el que se da sentido a las condiciones de vida de estas personas. La apropiación que realizan remite a un trabajo simbólico que hace eje en elaborar problemáticas que son consideradas centralmente como de carácter personal: las drogas, los amores contrariados, la muerte de seres queridos, la pobreza en el hogar.

8 En este registro, como señala Algranti (2010), "la desigual distribución de los riesgos y peligros relacionados con procesos sociales de gran escala como son las crisis económicas, la flexibilización laboral, el aumento de la pobreza, las dificultades de acceso a la salud o la emergencia habitacional, impactan directamente en las biografías familiares e individuales, radicalizando el sentimiento de inadecuación entre el sujeto y el mundo social" (pp. 115-116).

9 Las pruebas son en este sentido "desafíos históricos, socialmente producidos, culturalmente representados, desigualmente distribuidos que los individuos están obligados a enfrentar en el seno de un proceso estructural de individuación" (Martuccelli \& Araujo, 2010, p. 83). 
En este cuadro, las banderas plasman ese trabajo simbólico que tiene diferentes acentos. En algunos casos prima la inscripción simbólica de situaciones dolorosas en una red de relaciones intersubjetivas, en las que la bandera es un emblema grupal; en otros casos, se manifiesta como central una tendencia individualizante - la bandera como objeto de un trabajo personal autocentrado en el yo-. Pero en todos los casos, este trabajo reflexivo no se reduce a la búsqueda de un sentido de pertenencia colectivo o a una identificación personal con el contenido de las letras que se oyen: los fans no escuchan esta música porque sus letras empáticamente reflejan su propia situación. Antes bien, la música que escuchan hace posible "trabajar de manera imaginaria los esquemas de su experiencia" (Lahire, 1998/2004). En esta clave, diversas situaciones de sus vidas cotidianas son abordadas a partir de la apropiación de un objeto de la cultura de masas que ofrece, junto a la musicalidad, un lenguaje polisémico que activa la interpretación personal de estas situaciones.

El recorrido por estos relatos ha mostrado, en suma, que la música puede servir como un recurso específico para elaborar simbólicamente experiencias trascendentes (darles sentido, procesarlas y resolverlas), que no encuentran elaboración en otros espacios o repertorios simbólicos de la vida social en los que participan estas personas. Es a través de este recurso que estos fans elaboran dimensiones de una condición juvenil específica. Esta especificidad no se relaciona con un a priori asociado a la edad como dato biológico, sino con el hecho de compartir un mismo campo de experiencias: aquel que resulta de la sedimentación de diversas formas de precariedad entrelazadas en ámbitos como el mundo laboral, el escolar, o el asociado a las condiciones del hábitat que se transita-, como correlato del retiro de instancias de regulación estatal. Este proceso, no del todo novedoso para esta generación, pero tampoco completamente naturalizado en las trayectorias personales, se articula con la importancia creciente de las culturas masivas en el otorgamiento de repertorios para la definición identitaria. Es desde estas coordenadas que hay que comprender a estos fans hacedores de banderas, porque desde ellas están elaborando su propia condición de jóvenes en el mundo popular.

\section{Lista de referencias}

Adorno, T., \& Horkheimer, M. (1944/1969). Dialéctica del iluminismo. Buenos Aires: Sudamericana.

Alabarces, P. (2008). Posludio: música popular, identidad, resistencia y tanto ruido (para tan poca furia). Trans. Revista Transcultural de Música, 12, s. pp.

Alabarces, P., \& Rodríguez, M. G. (Comps.) (1996). Cuestión de pelotas: fútbol, deporte, sociedad y cultura. Buenos Aires: Atuel.

Algranti, J. (2010). Apontamentos sobre a mudança religiosa na Argentina. Aproximações ao estudo das formas de conversão e passagem no mundo neopentecostal. Rever. Revista de Estudos da Religião, 10, 99-119.

Aliano, N. (2010). Culturas populares: orientaciones y perspectivas a partir del análisis de un campo de estudios. Sociohistórica. Cuadernos del Cish, 27, 185-209.

Aliano, N.(2015). Música, afición y subjetividad entre seguidores del Indio Solari: un estudio sobre procesos de individuación en sectores populares. (Tesis presentada para optar por el título de Doctor en Ciencias Sociales). Universidad Nacional de La Plata, La Plata, Argentina.

Aliano, N., López, M., Pinedo, J., Stefoni, A., \& Welschinger, N. (2010). "Banderas en tu corazón": narrativas identitarias, vida cotidiana y prácticas de apropiación de la música rock en los sectores populares contemporáneos. Cuestiones de Sociología. Revista de Estudios Sociales, 6, 165-184.

Blázquez, G. (2014). ¡Bailaló! Género, raza y erotismo en el Cuarteto Cordobés. Buenos Aires: Gorla.

Bourdieu, P. (1979/2012). La distinción: criterio y bases sociales del gusto. Buenos Aires: Taurus.

Carozzi, M. (1993). Consultando a una Mãe de Santo: un análisis de la construcción 
social del efecto mágico. Revista de Investigaciones Folklóricas, 8, 68-79.

Carozzi, M. (2015). Aquí se baila tango: una etnografía de las milongas porteñas. Buenos Aires: Siglo XXI.

Chaves, M. (2017). Jóvenes entre el centro y la periferia de la ciudad, del Estado y de la academia. Ciudadanías. Revista de Politicas Sociales Urbanas, 1, s. pp.

Da Matta, R. (2002). Carnavales, malandros y héroes: hacia una sociología del dilema brasileño. México D. F.: Fondo de Cultura Económica.

De Nora, T. (2000). Music in everydaylife. Cambridge: Cambridge University Press.

Di Leo, P., \& Camarotti, A. (2017). Relatos biográficos y procesos de individuación juveniles en barrios marginalizados de Argentina. Revista Latinoamericana de Ciencias Sociales, Niñez y Juventud, 15(2), 1021-1034. doi:10.11600/169271 $5 \mathrm{x} .1521530082016$

Frith, S. (1996/2003). Música e identidad. En S. Hall, \& P. du Gay (Comps.), Cuestiones de identidad cultural (pp. 181-213). Buenos Aires: Amorrortu.

Gallo, G. (2011). Poder bailar lo que me pinta: movimientos libres, posibles y observados en pistas de baile electrónicas. En M. Carozzi (Comp.), Las palabras y los pasos: etnografías de la danza de la ciudad (pp. 47-82). Buenos Aires: Gorla.

Garriga, J., \& Salerno, D. (2008). Estadios, hinchas y rockeros: variaciones sobre el aguante. En P. Alabarces, \& M. G. Rodríguez (Comps.), Resistencias y mediaciones: estudios sobre cultura popular (pp. 59-88). Buenos Aires: Paidós.

Guerrero, G. (2005). Indio Solari: el hombre ilustrado. Buenos Aires: Sudamericana.

Hebdige, D. (1979/2004). Subcultura: el significado del estilo. Barcelona: Paidós.

Kessler, G. (2009). El sentimiento de inseguridad: sociología del temor al delito. Buenos Aires: Siglo XXI.

Kessler, G. (2013). Ilegalismos en tres tiempos. En R. Castel et al. (Eds.), Individuación, precariedad, inseguridad, ¿desinstitucionalización del presente? (pp. 109-165). Buenos Aires: Paidós.
Lahire, B. (1998/2004). El hombre plural: los resortes de la acción. Barcelona: Bellaterra.

Lenarduzzi, V. (2016). La pista de baile: escena de la comunicación contemporánea. La Trama de la Comunicación, 20(2), 91-109.

Martuccelli, D., \& Araujo, K. (2010). La individuación y el trabajo de los individuos. Educação e Pesquisa, 36, São Paulo, 7791.

Papalini, V. (2016). Garantías de felicidad: estudio sobre los libros de autoayuda. Buenos Aires: Adriana Hidalgo Editora.

Petit, M. (2001). Lecturas: del espacio íntimo al espacio público. México D. F.: Fondo de Cultura Económica.

Ricoeur, P. (1990/1996). Sí mismo como otro. Madrid: Siglo XXI.

Semán, P. (2006). Bajo continuo: exploraciones descentradas sobre cultura popular $y$ masiva. Buenos Aires: Gorla.

Semán, P. (2011). Introducción. Revista Argentina de Estudios de Juventud, 4, 1-20.

Semán, P., \& P. Vila (2011). Cumbia villera: una narrativa de mujeres activadas. en P. Semán, \& P. Vila (Comps.), Cumbia: nación, etnia y género en Latinoamérica (pp. 29-99). Buenos Aires: Gorla.

Spataro, C. (2013). ¿A qué vas a ese lugar?: mujeres, tiempo de placer y cultura de masas. Papeles de Trabajo, 11(7), 188-206.

Sustas, S., \& Touris, M. (2013). Refugios afectivos: el amor en los nuevos tiempos. En P. Di Leo, \& A. Camarotti (Eds.), Quiero escribir mi historia: vidas de jóvenes en barrios populares (pp. 33-50). Buenos Aires: Biblos.

Vila, P. (1996). Identidades narrativas y música: una primera propuesta para entender sus relaciones. Trans. Revista Transcultural de Música, 2, s. pp. 